\title{
Rising Prevalence and Neighborhood, Social, and Behavioral Determinants of Sleep Problems in US Children and Adolescents, 2003-2012
}

\author{
Gopal K. Singh and Mary Kay Kenney \\ US Department of Health and Human Services, Health Resources and Services Administration, Maternal and Child Health Bureau, \\ 5600 Fishers Lane, Room 18-41, Rockville, MD 20857, USA \\ Correspondence should be addressed to Gopal K. Singh; gsingh@hrsa.gov
}

Received 28 March 2013; Accepted 10 May 2013

Academic Editor: Giora Pillar

Copyright (C) 2013 G. K. Singh and M. K. Kenney. This is an open access article distributed under the Creative Commons Attribution License, which permits unrestricted use, distribution, and reproduction in any medium, provided the original work is properly cited.

\begin{abstract}
We examined trends and neighborhood and sociobehavioral determinants of sleep problems in US children aged 6-17 between 2003 and 2012. The 2003, 2007, and 2011-2012 rounds of the National Survey of Children's Health were used to estimate trends and differentials in sleep problems using logistic regression. Prevalence of sleep problems increased significantly over time. The proportion of children with $<7$ days/week of adequate sleep increased from 31.2\% in 2003 to 41.9\% in 2011-2012, whereas the prevalence of adequate sleep $<5$ days/week rose from $12.6 \%$ in 2003 to $13.6 \%$ in 2011-2012. Prevalence of sleep problems varied in relation to neighborhood socioeconomic and built-environmental characteristics (e.g., safety concerns, poor housing, garbage/litter, vandalism, sidewalks, and parks/playgrounds). Approximately $10 \%$ of children in neighborhoods with the mostfavorable social environment had serious sleep problems, compared with $16.2 \%$ of children in neighborhoods with the leastfavorable social environment. Children in neighborhoods with the fewest health-promoting amenities or the greatest social disadvantage had $37 \%-43 \%$ higher adjusted odds of serious sleep problems than children in the most-favorable neighborhoods. Higher levels of screen time, physical inactivity, and secondhand smoke exposure were associated with $20 \%-47 \%$ higher adjusted odds of sleep problems. Neighborhood conditions and behavioral factors are important determinants of sleep problems in children.
\end{abstract}

\section{Introduction}

Sleep problems in children have significant impacts on their health and well-being [1-4]. Inadequate sleep in children has been shown to be associated with poor academic performance, behavioral problems, poor mental and physical health, obesity and weight gain, alcohol use, accidents, and injuries [1-15]. Research also suggests that these adverse health effects vary in relation to the amount or duration of sleep problems [2-6, 12-15]. The US data show that, compared to children and adolescents who do not experience any sleep problems during the week, those who experience inadequate sleep during the entire week have 3-4 times higher risks of serious behavioral problems, 4-5 times higher risks of depression and anxiety, 2.5 times higher risk of $\mathrm{ADD} / \mathrm{ADHD}$, 3.2 times higher risk of migraine headaches, 1.5 times higher risk of being in fair/poor overall health, 1.6 times higher risk of repeating a grade or having a problem at school, and 2.8 times higher risk of missing $>2$ weeks of school during a year [16-18].

Past research has examined the impact of a number of sociodemographic and behavioral factors on childhood sleep problems $[1,2,4,19-23]$. These factors include child's age, gender, race/ethnicity, household socioeconomic status (SES), and such behavioral risk factors as physical activity, television viewing, and recreational computer use $[1,2,4$, 19-23]. Although the effects of neighborhood factors have been examined for a number of child health and behavioral outcomes such as physical inactivity, obesity, school performance, perceived health status, mental health, behavioral problems, and youth violence [16, 24-31] few studies have addressed the relationship between neighborhood environments and children's sleep problems $[1,2,32]$. To our knowledge, the impact of neighborhood social conditions 
and built environments on sleep problems in the US has not been fully explored using a nationally representative sample of school-aged children.

Analyzing the health effects of neighborhood environment is important because neighborhood conditions reflect the broader social and community contexts within which variations in individual health and social behaviors occur $[16,24-27,33]$. Many aspects of neighborhood environment that are thought to influence child health and behavioral outcomes, such as socioeconomic deprivation, poor housing, crime, and lack of social amenities, are potentially modifiable through social policies $[16,24,25,34]$. Additionally, neighborhood conditions have been linked to a variety of health and behavioral outcomes among both children and adults, including obesity and physical activity, infant mortality, low birthweight, smoking, self-rated health, mental health, injury, and mortality $[16,24-26,33]$. As such, improvements in neighborhood environment have the potential to positively impact a wide range of childhood health inequalities, including those in sleep problems [16, 26]. Emphasis on the neighborhood environment and broader social structure is also consistent with the Healthy People 2020 objectives [35].

Besides neighborhood factors, examining the sleep effects of household SES, race/ethnicity, and behavioral characteristics is important as well because they identify additional opportunities to reduce health disparities among children through targeted interventions. Moreover, health-related behaviors, which are amenable to change through public policy and social interventions, are one possible mechanism through which neighborhood, ethnic, and social factors might influence sleep patterns in children.

The National Survey of Children's Health (NSCH) allows us to explore the association between neighborhood conditions, household SES, behavioral risk factors, and childhood sleep problems in the US. In this study, we (1) examine trends in prevalence of sleep problems by child's age, gender, and race/ethnicity, (2) estimate prevalence of sleep problems by a variety of neighborhood, household, and child-level characteristics, (3) assess whether neighborhoods effects on sleep problems persist after adjusting for household SES and sociodemographic characteristics, (4) examine the potential intervening mechanisms, particularly behavioral factors of physical activity, recreational screen time, and exposure to secondhand smoke (SHS), through which neighborhood conditions may influence sleep patterns, and (5) examine whether the sleep effects of neighborhood environment and behavioral factors vary by child's age and gender.

\section{Methods}

Trends in prevalence of sleep problems by age, gender, and race/ethnicity were analyzed using the 2003, 2007, and 2011-2012 NSCH [18, 36-41]. However, data for the detailed analyses of neighborhood, socioeconomic, and behavioral determinants came from the $2007 \mathrm{NSCH}$ because it had the most complete information on covariates, including composite neighborhood indices [18, 36, 37, 40]. All three rounds of the survey were conducted by the National Center for Health Statistics (NCHS), with funding and direction from the Maternal and Child Health Bureau [36-39]. The purpose of the NSCH was to provide national and statespecific prevalence estimates for a variety of children's health and well-being indicators [36-39]. The surveys included an extensive array of questions about children's health and the family, including parental health, stress and coping behaviors, family activities, and parental concerns about their children $[18,36-41]$. Interviews were conducted with parents, and special emphasis was placed on factors related to children's well-being.

All three rounds of the NSCH were cross-sectional telephone surveys. The 2003 survey was conducted between January 2003 and July 2004; the 2007 survey was conducted between April 2007 and July 2008; and the 2011-2012 survey was conducted between February 2011 and June 2012 [18, 3641]. The sample size was 102,353 children $<18$ years of age for the 2003 survey, 91,642 for the 2007 survey, and 95,677 for the 2011-2012 survey. In each survey, the average sample size was about 1,800-2,000 children per state [18, 36-41]. In all three rounds of the survey, a random-digit-dial sample of households with children $<18$ years of age was selected from each of the 50 states and the District of Columbia. One child was selected from all children in each identified household to be the subject of the survey [18, 36-41]. Interviews were conducted in English, Spanish, and four Asian languages. The respondent was the parent or guardian who knew most about the child's health status and health care. All survey data were based on parental reports. The interview completion rate for the NSCH, measuring the percentage of completed interviews among known households with children, was $68.8 \%$ in $2003,66.0 \%$ in 2007 , and $54.1 \%$ for the landline sample and $41.2 \%$ for the cell-phone sample in 2011-2012 [37-39]. The overall response rate at the national level was $55.3 \%$ in 2003 and $46.7 \%$ in $2007[37,38]$.The overall response rate for the 2011-2012 survey is not yet available. Substantive and methodological details of the 2003, 2007, and 2011-2012 surveys are described elsewhere [36-41]. The NCHS Research Ethics Review Board approved all data collection procedures for each round of the survey.

The sample size for the detailed covariate analysis, based on the $2007 \mathrm{NSCH}$, was 63,352 children and adolescents aged 6-17. The dependent variable, sleep problems, was based on the question "During the past week, on how many nights did the child get enough sleep for a child his/her age?" From this question, we derived two measures of inadequate sleep: children who experienced $<7$ days/week of adequate sleep (or at least 1 day/week of inadequate sleep) and those who experienced $<5$ days/week of adequate sleep (or at least 3 days/week of inadequate sleep) [16, 17, 42]. The latter measure, representing more serious sleep problems, tends to capture the amount of sleep problems and may be clinically more relevant as it leads to stronger physical and mental health effects $[16,17,42]$.

Neighborhood social conditions and built environments were the primary covariates of interest. Neighborhood social conditions included dichotomous measures of perceived neighborhood safety, presence of garbage/litter in the neighborhood, poor/dilapidated housing, and vandalism such as broken windows or graffiti [26]. We used a previously 


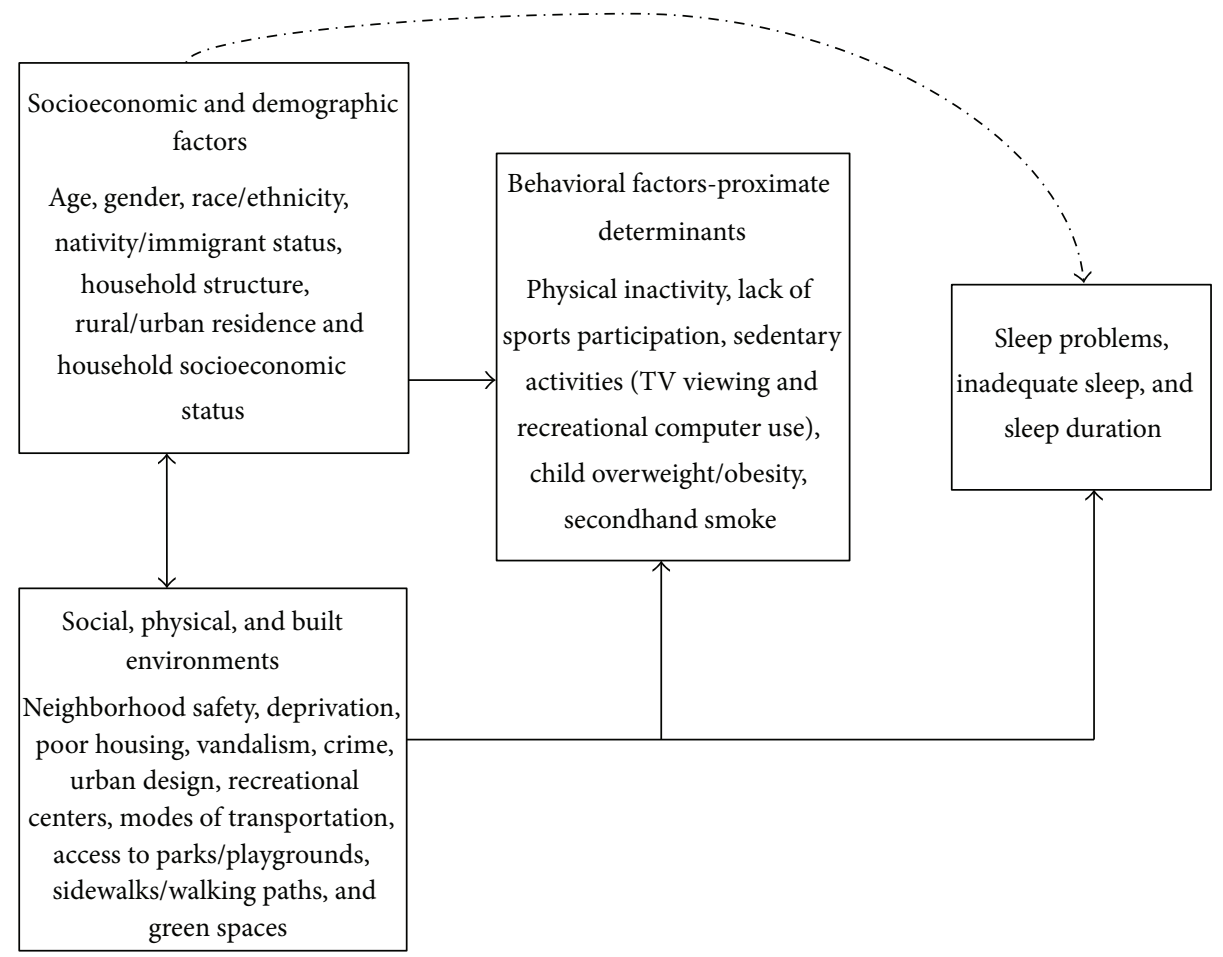

FIGURE 1: A simple model of neighborhood and sociobehavioral determinants of sleep problems in children and adolescents.

developed factor-based index of neighborhood social conditions that combined the above four neighborhood social indicators with respective factor loadings or weights of 0.52 , $0.69,0.71$, and 0.72 [26]. Higher scores on the neighborhood social conditions index $($ alpha $=0.57)$ represent more favorable socioeconomic conditions. The built environment index, developed previously, consisted of 4 variables: neighborhood access to sidewalks/walking paths; parks/playgrounds; recreation or community centers; and library/bookmobile, with respective factor loadings of $0.69,0.75,0.66$, and 0.67 [26]. Higher scores on the built environment index $($ alpha $=0.64)$ represent higher levels of health-promoting neighborhood amenities. Both indices were standardized to have a mean score of 100 and standard deviation of 20 . Note that the two neighborhood indices were orthogonal or independent of each other [26]. Two indicators of household SES were used: parental education and household income/poverty levels.

We used social determinants of health framework to model links between neighborhood conditions, household socioeconomic characteristics, health-related behaviors, and childhood sleep problems (Figure 1) [16, 25, 26, 28, 43, 44]. Within this framework, neighborhood and household socioeconomic characteristics are considered underlying determinants, $[16,25,26,28,43,44]$ which may influence sleep patterns by creating conditions (e.g., noise, violence, and anxiety) that lead to sleep disturbance in children. They are also hypothesized to affect sleep problems indirectly through their effects on intervening psychosocial and behavioral mechanisms such as familial stress and behavioral risk factors such as physical activity, television viewing, alcohol, tobacco and substance use, and SHS exposure $[16,26,28]$.
A bidirectional relationship between household SES and neighborhood conditions is postulated as neighborhood social and built environment conditions can influence household or individual education and income attainment, employment status, and housing tenure. On the other hand, age and racial/ethnic composition, household socioeconomic conditions, and place of residence can contribute significantly to the makeup of the neighborhoods, community economic development, and the kinds of social and physical amenities that might be available to neighborhood or community residents [16, 26, 28, 43, 44].

Using this framework and past research as a guide, we considered twelve covariates of childhood sleep problems, in addition to the neighborhood conditions. These included child's age, gender, race/ethnicity, nativity/immigrant status, household composition, metropolitan/non-metropolitan residence, household/parental education $(<12,12,13-15, \geq 16$ years), household poverty status measured as a ratio of family income to the poverty threshold $(<100 \%, 100-199 \%, 200-$ $399 \%, \geq 400 \%$ ), television viewing, recreational computer use, physical activity levels, and SHS exposure $[1,2,4,16$, $19-23,26,28]$. SHS exposure was determined by whether anyone smoked inside child's home. All other covariates were measured as shown in Tables 1-4.

Income was imputed for $9 \%$ of the observations by using a multiple imputation technique [37]. For all other covariates, there were few or no missing cases, which were excluded from the multivariate analyses.

The $\chi^{2}$ statistic was used to test the overall association between covariates and sleep problems. The $t$-statistic was used to test the difference in prevalence between any two 


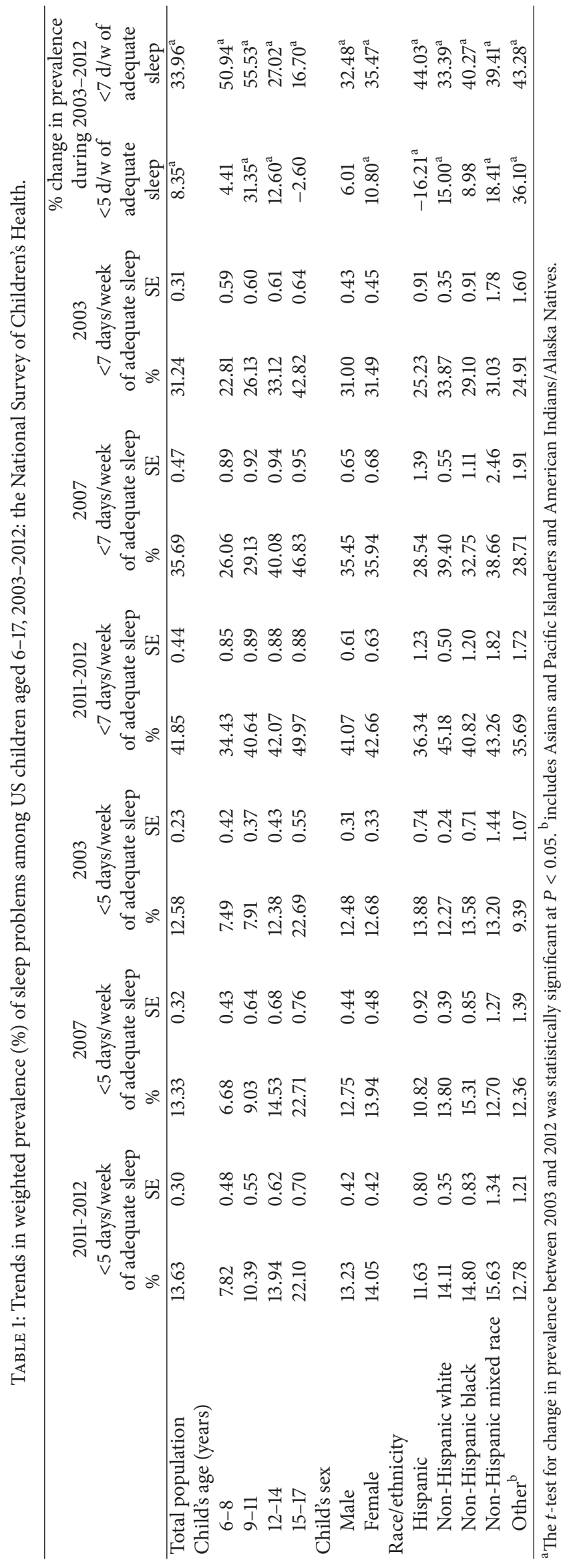


TABLE 2: Descriptive statistics of the sample for children aged 6-17 years, according to neighborhood, sociodemographic, and behavioral characteristics: the 2007 National Survey of Children's Health $(N=63,352)$.

\begin{tabular}{|c|c|c|}
\hline $\begin{array}{l}\text { Sociodemographic and behavioral } \\
\text { characteristics }\end{array}$ & $\begin{array}{l}\text { Unweighted } \\
\text { number in } \\
\text { sample }\end{array}$ & $\begin{array}{c}\text { Weighted } \\
\text { percent in } \\
\text { sample }\end{array}$ \\
\hline \multicolumn{3}{|l|}{$\begin{array}{l}\text { Index of neighborhood } \\
\text { socioeconomic conditions }\end{array}$} \\
\hline 20.78-67.09 (least favorable) & 4,618 & 8.88 \\
\hline $67.10-88.32$ & 4,187 & 7.31 \\
\hline $88.33-104.99$ & 10,635 & 17.62 \\
\hline $105.00-111.40$ (most favorable) & 42,981 & 66.19 \\
\hline \multicolumn{3}{|l|}{ Neighborhood safety } \\
\hline Safe & 56,356 & 86.57 \\
\hline Unsafe & 6,328 & 13.43 \\
\hline \multicolumn{3}{|l|}{$\begin{array}{l}\text { Presence of garbage/litter in } \\
\text { neighborhood }\end{array}$} \\
\hline Yes & 9,427 & 16.04 \\
\hline No & 53,348 & 83.96 \\
\hline \multicolumn{3}{|l|}{$\begin{array}{l}\text { Poorly kept or dilapidated/rundown } \\
\text { housing in neighborhood }\end{array}$} \\
\hline Yes & 8,717 & 14.21 \\
\hline No & 53,981 & 85.79 \\
\hline \multicolumn{3}{|l|}{$\begin{array}{l}\text { Vandalism such as broken windows } \\
\text { or graffiti in neighborhood }\end{array}$} \\
\hline Yes & 6,007 & 11.17 \\
\hline No & 56,757 & 88.83 \\
\hline \multicolumn{3}{|l|}{$\begin{array}{l}\text { Index of neighborhood built } \\
\text { environment }\end{array}$} \\
\hline 46.40-67.04 (low amenities) & 5,121 & 8.53 \\
\hline $67.05-81.39$ & 8,227 & 12.02 \\
\hline $81.40-104.99$ & 20,306 & 32.40 \\
\hline 105.00-116.40 (high amenities) & 28,193 & 47.05 \\
\hline \multicolumn{3}{|l|}{$\begin{array}{l}\text { Neighborhood access to sidewalks } \\
\text { or walking paths }\end{array}$} \\
\hline Yes & 43,947 & 72.19 \\
\hline No & 18,840 & 27.81 \\
\hline \multicolumn{3}{|l|}{$\begin{array}{l}\text { Neighborhood access to parks or } \\
\text { playgrounds }\end{array}$} \\
\hline Yes & 49,025 & 79.33 \\
\hline No & 13,768 & 20.67 \\
\hline \multicolumn{3}{|l|}{$\begin{array}{l}\text { Neighborhood access to a } \\
\text { recreation or community center }\end{array}$} \\
\hline Yes & 39,915 & 64.95 \\
\hline No & 22,132 & 35.05 \\
\hline \multicolumn{3}{|l|}{$\begin{array}{l}\text { Neighborhood access to a library or } \\
\text { bookmobile }\end{array}$} \\
\hline Yes & 54,594 & 86.33 \\
\hline No & 8,122 & 13.67 \\
\hline \multicolumn{3}{|l|}{ Child's age (years) } \\
\hline $6-8$ & 13,512 & 24.55 \\
\hline 9-11 & 14,083 & 24.23 \\
\hline $12-14$ & 16,338 & 26.00 \\
\hline $15-17$ & 19,419 & 25.22 \\
\hline \multicolumn{3}{|l|}{ Child's sex } \\
\hline Male & 32,981 & 51.15 \\
\hline Female & 30,371 & 48.85 \\
\hline
\end{tabular}

TABLE 2: Continued.

\begin{tabular}{|c|c|c|}
\hline $\begin{array}{l}\text { Sociodemographic and behavioral } \\
\text { characteristics }\end{array}$ & $\begin{array}{l}\text { Unweighted } \\
\text { number in } \\
\text { sample }\end{array}$ & $\begin{array}{c}\text { Weighted } \\
\text { percent in } \\
\text { sample }\end{array}$ \\
\hline \multicolumn{3}{|l|}{ Race/ethnicity } \\
\hline Non-Hispanic white & 43,444 & 56.53 \\
\hline Non-Hispanic black & 6,363 & 14.81 \\
\hline Hispanic & 7,245 & 18.85 \\
\hline American Indian/Alaska native & 818 & 0.83 \\
\hline Asian & 1,452 & 3.33 \\
\hline Hawaiian/Pacific Islander & 309 & 0.34 \\
\hline Non-Hispanic mixed race & 2,753 & 3.74 \\
\hline Other & 968 & 1.56 \\
\hline \multicolumn{3}{|l|}{ Child's nativity/immigrant status } \\
\hline Born to immigrant parents & 7,964 & 19.02 \\
\hline Born to US-born parents & 55,388 & 80.98 \\
\hline \multicolumn{3}{|l|}{ Household composition } \\
\hline Two-parent biological & 41,673 & 62.49 \\
\hline Two-parent stepfamily & 5,984 & 10.12 \\
\hline Single mother & 10,744 & 19.76 \\
\hline Other family type & 4,951 & 7.63 \\
\hline \multicolumn{3}{|l|}{ Place of residence } \\
\hline Metropolitan & 43,859 & 83.69 \\
\hline Non-metropolitan & 19,493 & 16.31 \\
\hline \multicolumn{3}{|l|}{$\begin{array}{l}\text { Household poverty status (ratio of } \\
\text { family income to poverty threshold) }\end{array}$} \\
\hline Below $100 \%$ & 6,886 & 17.08 \\
\hline $100 \%-199 \%$ & 10,500 & 20.51 \\
\hline $200 \%-399 \%$ & 21,624 & 32.17 \\
\hline At or above $400 \%$ & 24,343 & 30.24 \\
\hline \multicolumn{3}{|l|}{$\begin{array}{l}\text { Highest household or parental } \\
\text { education level (years) }\end{array}$} \\
\hline$<12$ & 3,666 & 8.47 \\
\hline 12 & 10,263 & 23.53 \\
\hline $13-15$ & 17,813 & 26.87 \\
\hline $16+$ & 30,193 & 41.13 \\
\hline \multicolumn{3}{|l|}{$\begin{array}{l}\text { Television watching (number of } \\
\text { hours per day) }\end{array}$} \\
\hline$<1$ & 13,282 & 20.66 \\
\hline 1 & 19,176 & 29.07 \\
\hline 2 & 18,252 & 28.41 \\
\hline$>2$ & 12,151 & 21.87 \\
\hline \multicolumn{3}{|l|}{$\begin{array}{l}\text { Recreational computer use (number } \\
\text { of hours per day) }\end{array}$} \\
\hline$<1$ & 30,663 & 51.30 \\
\hline $1-2$ & 24,036 & 38.23 \\
\hline$>2$ & 6,352 & 10.47 \\
\hline \multicolumn{3}{|l|}{$\begin{array}{l}\text { Physical activity (number of days } \\
\text { per week) }\end{array}$} \\
\hline 0 & 5,649 & 10.21 \\
\hline $1-2$ & 7,571 & 12.36 \\
\hline $3-4$ & 15,529 & 23.95 \\
\hline $5+$ & 34,096 & 53.48 \\
\hline \multicolumn{3}{|l|}{ Secondhand smoke exposure } \\
\hline Yes & 5,293 & 8.93 \\
\hline No & 57,620 & 91.07 \\
\hline
\end{tabular}


TABLE 3: Weighted prevalence of sleep problems among US children aged 6-17 by neighborhood, sociodemographic, and behavioral characteristics: the 2007 National Survey of Children's Health $(N=63,352)$.

\begin{tabular}{|c|c|c|c|c|c|c|}
\hline \multirow{2}{*}{ Sociobehavioral characteristic } & \multicolumn{3}{|c|}{ Less than 5 days/week of adequate sleep } & \multicolumn{3}{|c|}{ Less than 7 days/week of adequate sleep } \\
\hline & $\%$ & SE & $P$ value & $\%$ & SE & $P$ value \\
\hline $\begin{array}{l}\text { Index of neighborhood socioeconomic } \\
\text { conditions }\end{array}$ & & & $<0.001$ & & & 0.282 \\
\hline 20.78-67.09 (least favorable) & 16.20 & 1.16 & & 38.20 & 1.70 & \\
\hline $67.10-88.32$ & 15.46 & 1.37 & & 37.80 & 1.96 & \\
\hline $88.33-104.99$ & 15.77 & 0.85 & & 35.44 & 1.08 & \\
\hline 105.00-111.40 (most favorable) & 12.10 & 0.38 & & 35.32 & 0.57 & \\
\hline Neighborhood safety & & & $<0.001$ & & & 0.588 \\
\hline Safe & 12.87 & 0.34 & & 35.89 & 0.50 & \\
\hline Unsafe & 16.62 & 1.01 & & 35.10 & 1.36 & \\
\hline Presence of garbage/litter in neighborhood & & & $<0.001$ & & & $<0.001$ \\
\hline Yes & 16.41 & 0.88 & & 39.33 & 1.17 & \\
\hline No & 12.77 & 0.35 & & 35.07 & 0.51 & \\
\hline $\begin{array}{l}\text { Poorly kept or dilapidated/rundown } \\
\text { housing in neighborhood }\end{array}$ & & & 0.005 & & & 0.083 \\
\hline Yes & 15.68 & 0.91 & & 37.76 & 1.27 & \\
\hline No & 12.95 & 0.35 & & 35.41 & 0.51 & \\
\hline $\begin{array}{l}\text { Vandalism such as broken windows or } \\
\text { graffiti in neighborhood }\end{array}$ & & & 0.030 & & & 0.192 \\
\hline Yes & 15.58 & 1.10 & & 37.68 & 1.58 & \\
\hline No & 13.08 & 0.34 & & 35.52 & 0.49 & \\
\hline Index of neighborhood built environment & & & 0.049 & & & 0.575 \\
\hline 46.40-67.04 (low amenities) & 15.68 & 1.32 & & 35.66 & 1.78 & \\
\hline $67.05-81.39$ & 14.68 & 0.88 & & 37.32 & 1.21 & \\
\hline $81.40-104.99$ & 13.53 & 0.56 & & 36.03 & 0.81 & \\
\hline 105.00-116.40 (high amenities) & 12.61 & 0.48 & & 35.38 & 0.7 & \\
\hline $\begin{array}{l}\text { Neighborhood access to sidewalks or } \\
\text { walking paths }\end{array}$ & & & 0.500 & & & 0.985 \\
\hline Yes & 13.22 & 0.40 & & 35.76 & 0.58 & \\
\hline No & 13.68 & 0.56 & & 35.78 & 0.79 & \\
\hline $\begin{array}{l}\text { Neighborhood access to parks or } \\
\text { playgrounds }\end{array}$ & & & 0.009 & & & 0.025 \\
\hline Yes & 12.90 & 0.35 & & 35.18 & 0.52 & \\
\hline No & 15.22 & 0.81 & & 37.85 & 1.06 & \\
\hline $\begin{array}{l}\text { Neighborhood access to a recreation or } \\
\text { community center }\end{array}$ & & & 0.120 & & & 0.557 \\
\hline Yes & 13.02 & 0.40 & & 36.03 & 0.58 & \\
\hline No & 14.10 & 0.57 & & 35.45 & 0.80 & \\
\hline $\begin{array}{l}\text { Neighborhood access to a library or } \\
\text { bookmobile }\end{array}$ & & & 0.031 & & & 0.743 \\
\hline Yes & 13.06 & 0.34 & & 35.90 & 0.50 & \\
\hline No & 15.39 & 1.03 & & 35.41 & 1.39 & \\
\hline Child's age (years) & & & $<0.001$ & & & $<0.001$ \\
\hline $6-8$ & 6.68 & 0.43 & & 26.06 & 0.89 & \\
\hline 9-11 & 9.03 & 0.64 & & 29.13 & 0.92 & \\
\hline $12-14$ & 14.53 & 0.68 & & 40.08 & 0.94 & \\
\hline $15-17$ & 22.71 & 0.76 & & 46.83 & 0.95 & \\
\hline
\end{tabular}


TABle 3: Continued.

\begin{tabular}{|c|c|c|c|c|c|c|}
\hline \multirow{2}{*}{ Sociobehavioral characteristic } & \multicolumn{3}{|c|}{ Less than 5 days/week of adequate sleep } & \multicolumn{3}{|c|}{ Less than 7 days/week of adequate sleep } \\
\hline & $\%$ & SE & $P$ value & $\%$ & SE & $P$ value \\
\hline Child's sex & & & 0.067 & & & 0.595 \\
\hline Male & 12.75 & 0.44 & & 35.45 & 0.65 & \\
\hline Female & 13.94 & 0.48 & & 35.94 & 0.68 & \\
\hline Race/ethnicity & & & 0.040 & & & $<0.001$ \\
\hline Non-Hispanic white & 13.80 & 0.39 & & 39.40 & 0.55 & \\
\hline Non-Hispanic black & 15.31 & 0.85 & & 32.75 & 1.11 & \\
\hline Hispanic & 10.82 & 0.92 & & 28.54 & 1.39 & \\
\hline American Indian/Alaska native & 13.12 & 2.55 & & 32.09 & 3.41 & \\
\hline Asian & 12.04 & 2.13 & & 26.96 & 2.94 & \\
\hline Hawaiian/Pacific Islander & 13.90 & 3.92 & & 36.17 & 7.86 & \\
\hline Non-Hispanic mixed race & 12.70 & 1.27 & & 38.66 & 2.46 & \\
\hline Other & 12.32 & 2.40 & & 29.01 & 3.02 & \\
\hline Child's nativity/immigrant status & & & $<0.001$ & & & $<0.001$ \\
\hline Born to immigrant parents & 10.33 & 0.79 & & 27.08 & 1.2 & \\
\hline Born to US-born parents & 14.04 & 0.35 & & 37.71 & 0.49 & \\
\hline Household composition & & & $<0.001$ & & & 0.585 \\
\hline Two-parent biological & 12.15 & 0.37 & & 35.38 & 0.58 & \\
\hline Two-parent stepfamily & 13.77 & 0.98 & & 35.55 & 1.57 & \\
\hline Single mother & 17.33 & 0.89 & & 36.99 & 1.05 & \\
\hline Other family type & 12.12 & 1.25 & & 35.03 & 1.84 & \\
\hline Place of residence & & & 0.102 & & & 0.064 \\
\hline Metropolitan & 13.50 & 0.37 & & 35.39 & 0.53 & \\
\hline Non-metropolitan & 12.46 & 0.52 & & 37.24 & 0.84 & \\
\hline $\begin{array}{l}\text { Household poverty status (ratio of family } \\
\text { income to poverty threshold) }\end{array}$ & & & 0.494 & & & $<0.001$ \\
\hline Below 100\% & 13.43 & 0.85 & & 30.32 & 1.14 & \\
\hline $100 \%-199 \%$ & 12.94 & 0.76 & & 32.29 & 1.06 & \\
\hline $200 \%-399 \%$ & 12.88 & 0.59 & & 37.09 & 0.86 & \\
\hline At or above $400 \%$ & 14.03 & 0.55 & & 39.55 & 0.81 & \\
\hline $\begin{array}{l}\text { Highest household or parental education } \\
\text { level (years) }\end{array}$ & & & 0.964 & & & $<0.001$ \\
\hline$<12$ & 13.09 & 1.26 & & 30.57 & 1.82 & \\
\hline 12 & 13.73 & 0.77 & & 34.29 & 1.07 & \\
\hline $13-15$ & 13.40 & 0.60 & & 34.94 & 0.88 & \\
\hline $16+$ & 13.31 & 0.47 & & 38.52 & 0.69 & \\
\hline $\begin{array}{l}\text { Television watching (number of hours per } \\
\text { day) }\end{array}$ & & & $<0.001$ & & & 0.996 \\
\hline$<1$ & 12.45 & 0.65 & & 36.02 & 1.04 & \\
\hline 1 & 12.64 & 0.61 & & 35.82 & 0.87 & \\
\hline 2 & 12.62 & 0.63 & & 35.76 & 0.87 & \\
\hline$>2$ & 16.12 & 0.73 & & 35.67 & 1.01 & \\
\hline $\begin{array}{l}\text { Recreational computer use (number of } \\
\text { hours per day) }\end{array}$ & & & $<0.001$ & & & $<0.001$ \\
\hline$<1$ & 9.93 & 0.38 & & 32.33 & 0.63 & \\
\hline $1-2$ & 15.89 & 0.60 & & 39.03 & 0.79 & \\
\hline$>2$ & 20.93 & 1.17 & & 43.05 & 1.59 & \\
\hline
\end{tabular}


TABLe 3: Continued.

\begin{tabular}{|c|c|c|c|c|c|c|}
\hline \multirow{2}{*}{ Sociobehavioral characteristic } & \multicolumn{3}{|c|}{ Less than 5 days/week of adequate sleep } & \multicolumn{3}{|c|}{ Less than 7 days/week of adequate sleep } \\
\hline & $\%$ & SE & $P$ value & $\%$ & SE & $P$ value \\
\hline Physical activity (number of days per week) & & & $<0.001$ & & & $<0.001$ \\
\hline 0 & 18.77 & 1.14 & & 37.83 & 1.55 & \\
\hline $1-2$ & 18.13 & 1.17 & & 40.65 & 1.42 & \\
\hline $3-4$ & 12.76 & 0.57 & & 36.24 & 0.90 & \\
\hline $5+$ & 11.27 & 0.41 & & 33.79 & 0.64 & \\
\hline Secondhand smoke exposure & & & $<0.001$ & & & 0.042 \\
\hline Yes & 17.88 & 1.07 & & 38.76 & 1.43 & \\
\hline No & 12.90 & 0.34 & & 35.43 & 0.50 & \\
\hline
\end{tabular}

$P$ values associated with chi-square tests for independence between each covariate and sleep problems.

Both neighborhood indices have a mean score of 100 and a standard deviation of 20.

groups or time points. Logistic regression was used to examine the association between neighborhood and behavioral characteristics and sleep problems, after adjusting for the above covariates. To account for the complex sample design of the NSCH, SUDAAN software was used to conduct all statistical analyses [45].

\section{Results}

3.1. Trends in the Prevalence of Sleep Problems, 2003-2012. The prevalence of sleep problems increased significantly between 2003 and 2012 (Table 1). The proportion of children with $<7$ days/week of adequate sleep increased from $31.2 \%$ in 2003 to $35.7 \%$ in 2007 and $41.9 \%$ in 2011-2012, whereas the prevalence of adequate sleep $<5$ days/week rose from $12.6 \%$ in 2003 to $13.6 \%$ in $2011-2012$. The number of children aged 6-17 with at least 1 day/week of sleep problems rose from an estimated 15.1 million in 2003 to 20.5 million in 2011-2012. The increase in prevalence of sleep problems was more pronounced among children aged 6-11 and females. During 2003-2012, while children in all racial/ethnic groups experienced a marked increase in sleep problems at least 1 day/week, the prevalence of serious ( $\geq 3$ days/week) sleep problems increased significantly only among white, mixedrace, and "other" children (Table 1).

3.2. Neighborhood and Sociobehavioral Disparities in Sleep Problems, 2007. Descriptive characteristics of the 2007 sample are shown in Table 2. Approximately 9\% of the child population lived in neighborhoods with the most-unfavorable social or built environments. Non-Hispanic white children were the largest racial/ethnic group (56.5\%), followed by Hispanics (18.9\%), blacks (14.8\%), and Asians (3.3\%). Approximately $17 \%$ of children lived below the poverty line, and $8.5 \%$ of children had parents who had less than a high school education. Approximately $22 \%$ of children watched television $>2$ hours/day, while $10.2 \%$ of children were physically inactive and $8.9 \%$ were exposed to secondhand smoke. Table 3 shows observed prevalence of childhood sleep problems in 2007 according to various neighborhood, sociodemographic, and behavioral characteristics. The prevalence of sleep problems varied significantly in relation to neighborhood socioeconomic and built-environmental characteristics. Approximately $10 \%$ of children in neighborhoods with the most-favorable social environment had serious sleep problems, compared with $16.2 \%$ of children in neighborhoods with the least-favorable social environment. Children living in unfavorable neighborhoods that were characterized by safety concerns, garbage/litter in streets/sidewalks, poor/dilapidated housing, or vandalism had 19\%-29\% higher prevalence of serious sleep problems than those in more favorable neighborhoods (Table 3 ).

Approximately $15.7 \%$ of children in neighborhoods with the fewest health-promoting amenities had serious sleep problems, compared with $12.6 \%$ of children in neighborhoods with the most health-promoting amenities (Table 3). Specifically, children living in neighborhoods with no access to parks and playgrounds had $8 \%$ and $18 \%$ higher risks of $\geq 1$ day/week and $\geq 3$ days/week of sleep problems, respectively, than those with access to these amenities.

The prevalence of sleep problems was positively associated with child's age. Approximately $47 \%$ of children aged $15-$ 17 experienced at least 1 day/week of sleep problems, compared to $26.1 \%$ of children aged $6-8$. The prevalence of more serious sleep problems was 3.4 times greater among older adolescents compared to younger children. Hispanic and Asian children had fewer sleep problems than white and black children, whereas children of immigrant parents had fewer sleep problems than those with US-born parents (Table 3). Higher parental education and income were associated with a higher prevalence of at least 1 day/week of sleep problems.

In terms of behavioral effects, higher levels of physical inactivity, recreational computer use, and SHS exposure were significantly associated with both $\geq 1$ day/week and $\geq 3$ days/week of sleep problems. Higher levels of television viewing were associated with only more serious sleep problems (Table 3).

Since the adjusted effects of neighborhood factors, household SES, and demographic factors were generally similar in both the sociodemographic and full sociobehavioral models, we only interpret the results from the full multivariate models in Table 4. Higher risks of sleep problems associated with unfavorable neighborhood social conditions persisted even after the adjustment of sociodemographic and behavioral 


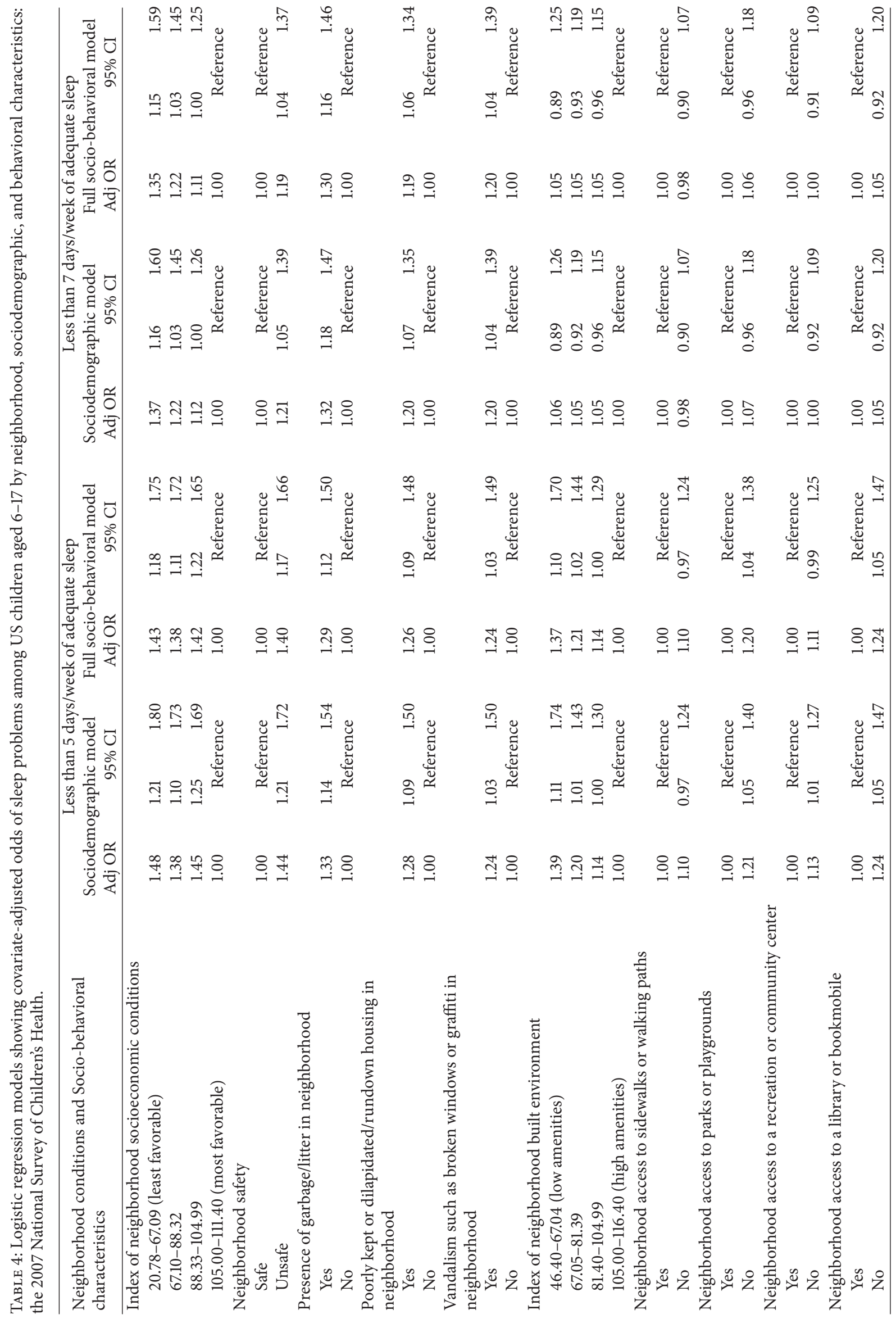




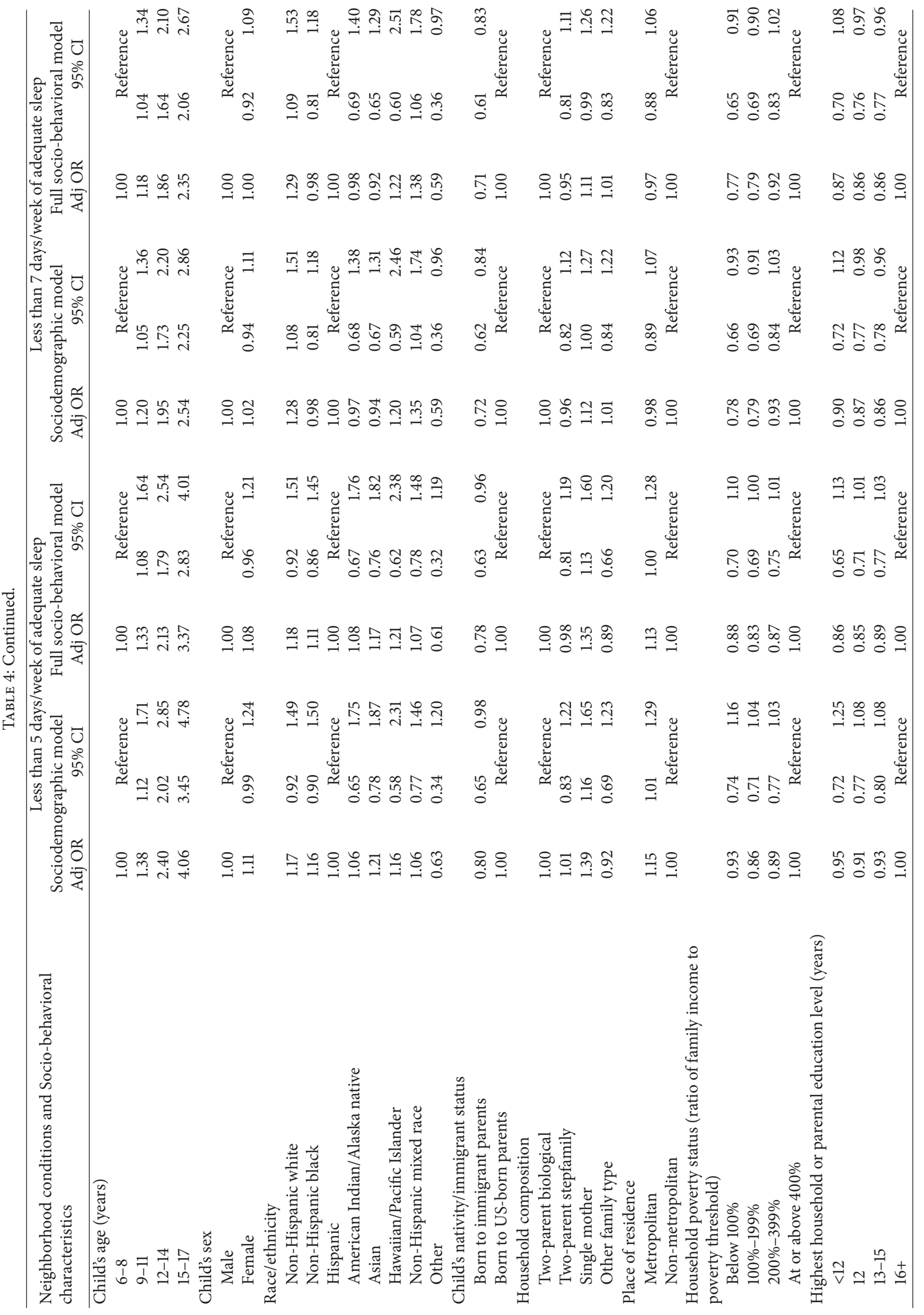




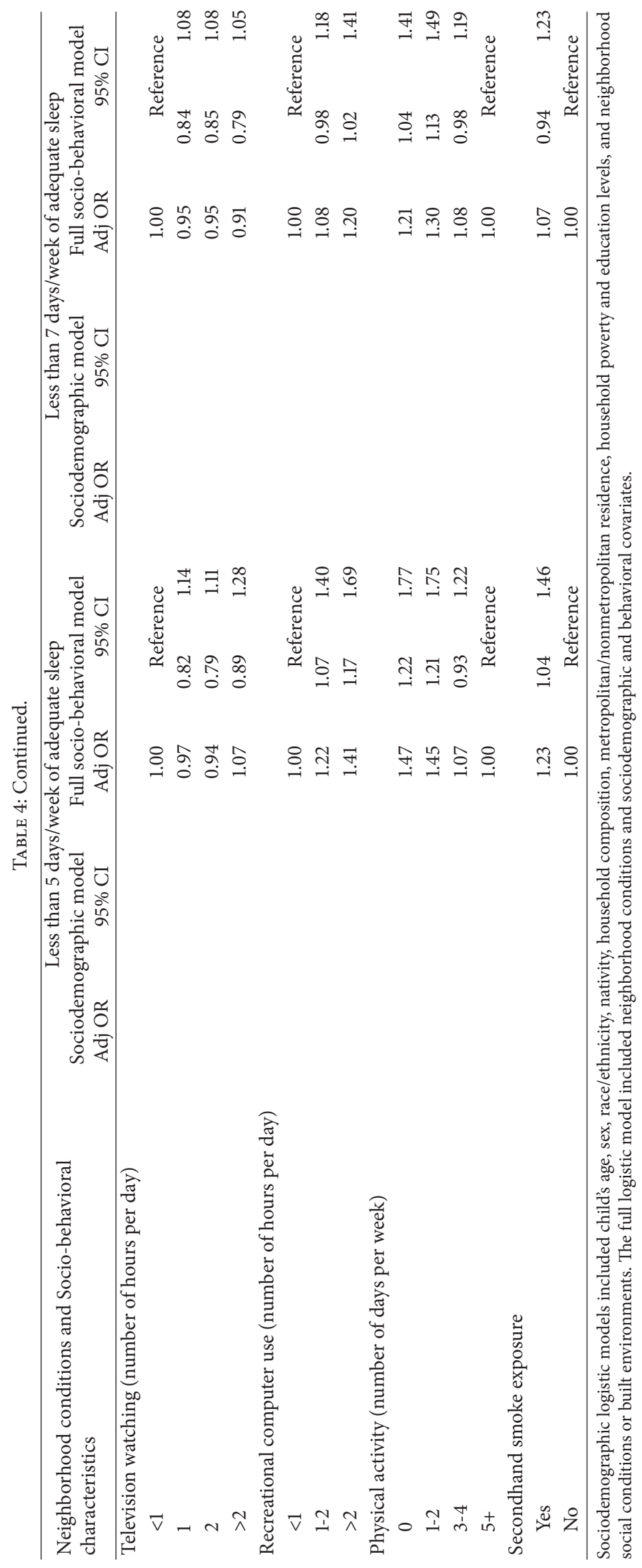


characteristics. Children in neighborhoods with the most unfavorable social conditions had $35 \%$ and $43 \%$ higher adjusted odds of $\geq 1$ day/week and $\geq 3$ days/week of sleep problems, respectively, than their counterparts from the mostfavorable neighborhood social environment. Each of the specific neighborhood social conditions was significantly related to both sleep measures. Children in neighborhoods with safety concerns, garbage/litter, poor/dilapidated housing, and vandalism had 40\%, 29\%, 26\%, and 24\% higher adjusted odds of serious sleep problems than children in neighborhoods without these unfavorable conditions, respectively (Table 4).

The built environment index was only significantly related to more serious sleep problems. Children in neighborhoods with the fewest health-promoting amenities had 37\% higher adjusted odds of serious sleep problems than children in neighborhoods with the most amenities. Not having an access to parks/playgrounds or a library/bookmobile was associated with $20 \%-24 \%$ higher adjusted odds of serious sleep problems. While there were no significant gender differentials in sleep problems, older adolescents aged 1517 had, respectively, 2.4 and 3.4 times higher odds of $\geq 1$ day/week and $\geq 3$ day/week of sleep problems than children aged 6-8. No significant racial/ethnic differentials were found for serious sleep problems; however, non-Hispanic white and mixed-race children had $29 \%$ and 38\% higher adjusted odds of experiencing at least 1 day/week of sleep problems than Hispanic children. Nativity remained a stronger risk factor, with children born to immigrant parents having $22 \%-$ $29 \%$ lower odds of sleep problems than children of USborn parents. Children in single-mother households had 35\% higher adjusted odds of serious sleep problems than those in two-parent households. Although household education or income was not significantly related to serious sleep problems, children from higher-SES households were significantly more likely to experience at least 1 day/week of sleep problems than children from lower-SES households (Table 4).

Neighborhood environments and household SES partly accounted for the effects of behavioral factors on sleep problems. Children with no physical activity had $21 \%$ and $47 \%$ higher adjusted odds of $\geq 1$ day/week and $\geq 3$ day/week of sleep problems, respectively, than children who exercised at least 5 days/week. Children with $>2$ hours/day of recreational computer use had $20 \%$ and $41 \%$ higher adjusted odds of $\geq 1$ day/week and $\geq 3$ day/week of sleep problems, respectively, than children with $<1$ hour/day of computer use. Children exposed to SHS had 23\% higher adjusted odds of serious sleep problems than those without exposure (Table 4).

We also examined interaction models of neighborhood, household SES, and behavioral factors by child's age (6-11, 12-17) and gender. However, none of the interactions were statistically significant, and the effects of the covariates on sleep problems were similar for males and females and for younger and older children and adolescents (data not shown).

\section{Discussion}

Sleep problems are increasingly being recognized as an important public health problem in the United States [3]. Our study showed a marked and consistent increase in the prevalence of childhood sleep problems between 2003 and 2012 . Currently, half of all adolescents aged 15-17 and more than one-third of young children aged 6-8, and approximately 21 million school-aged children and adolescents in the US are reported to have at least 1 day/week of sleep problems. What might account for this substantial increase in prevalence? It is conceivable that changes in the social, built, or obesogenic environments, demographic composition of the population, and physical inactivity levels or other sedentary activities may have contributed to the rise in sleep problems among US children-but a more formal analysis of the 2003, 2007, and 2011-2012 National Surveys of Children's Health is needed to shed more light on the rising trend.

To our knowledge, our study is the first to examine variations in sleep problems according to a variety of neighborhood and behavioral factors using a large, nationally representative sample of school-aged children and adolescents. In addition to neighborhood influences, assessing effects of screen time, physical inactivity, and SHS exposure on sleep problems in children represented an important aspect of our study. Increased risks of sleep problems associated with excess television viewing, recreational screen time, physical inactivity, and SHS exposure were independent of neighborhood conditions and household SES, and are consistent with those reported previously in the US and international studies $[1,4,19,20,22,23]$.

Neighborhood effects reported here are consistent with limited research that shows higher risks of sleep problems in children associated with unsafe school or neighborhood environment and greater area-based neighborhood distress or socioeconomic disadvantage $[1,2,32]$. In our study, the association between neighborhood factors and sleep problems was not explained or mediated by household SES and behavioral characteristics. Thus, most of the neighborhood effects reported here appear to be either direct or operate through psychosocial or behavioral mechanisms (such as parental stress, family conflict, family cohesiveness, social support, alcohol and substance use) that we did not consider in our analysis.

While neighborhood effects on childhood obesity, physical activity, and mental health have been shown to vary according to child's age and gender, $[16,24,26,28]$ we did not find similar patterns for sleep problems. Thus, when it comes to sleep problems, boys and girls as well as younger and older children appear to be equally vulnerable to unfavorable neighborhood environments.

Higher prevalence of sleep problems in children from higher-SES households is consistent with the patterns observed previously for children and adults in the US and elsewhere $[1,2,19,46]$. However, some studies have shown an inverse association between SES and sleep problems [4, $20,47]$. The inconsistent SES patterns in sleep behavior across studies may partly be due to differences in sleep measures and data sources [1].

A major strength of our study includes estimating the effects of a variety of neighborhood conditions and composite indices of neighborhood environment on children's sleep problems. Another important contribution of this study is the 
concurrent evaluation of the impact of both neighborhood factors and health behaviors on sleep problems. Although many features of the neighborhood environment may directly lead to sleep problems (such as noise, violence, and safety fears), we have identified possible casual pathways such as excessive television viewing, physical inactivity, recreational screen time, and SHS exposure which are potentially modifiable through public health policies. Examining specific features of the neighborhood environment brings us closer to intervention (e.g., better amenities, built environments, neighborhood revitalization, crime reduction, affordable housing, community safety, and safe streets) that could lead to better sleep health. The other strengths of our study include the large sample size, the generalizability of our findings, and examination of whether sleep effects of neighborhood conditions, household SES, and behavioral factors vary by age and gender.

This study has limitations. Children's behavioral measures, including sleep behavior, in the NSCH were based on parental reports and may not accurately reflect the true prevalence, particularly among older adolescents. However, prevalence of inadequate sleep reported here is consistent with that reported in other epidemiologic studies [1, 48, 49]. Moreover, previous research has indicated self- or parental reports to be reliable and valid reports of children's sleep patterns and disturbances and has shown satisfactory agreement between objective measures such as actigraphy and parent-report or survey-based measures [50-54]. Second, although neighborhood characteristics considered in our study are important measures of the social environment, they are perceived or parent-reported measures. While subjective ratings of the neighborhood environment may result in underestimation of the neighborhood effects on sleep health, both subjective and objective measures of the neighborhood environment are needed $[26,33]$. Third, same-source bias is a possible limitation since neighborhood conditions and sleep problems were reported by the same respondents $[16,55]$. The effects of neighborhood conditions on sleep problems could have been underestimated if disadvantaged individuals provided a more positive assessment of neighborhood environment $[16,33,55]$. Individuals in disadvantaged neighborhoods may be more optimistic about their neighborhood situation and, consequently, may downgrade the severity of problems facing their neighborhood surroundings, a phenomenon called "psychological adjustment" [16, 33, 55]. Fourth, our sleep measures were based on parental response to a single question regarding adequacy of child's sleep. No information in the survey was available about sleep quality, sleep duration, and types of sleep problems such as obstructive sleep apnea, difficulty falling or staying asleep through the night, and daytime sleepiness. Fifth, because of the cross-sectional nature of the $\mathrm{NSCH}$, causal inferences about the relationships between neighborhood environment, household SES, behavioral factors, and childhood sleep problems cannot be drawn $[16,17,26]$. Sixth, as with most sample surveys, the potential for nonresponse bias exists for the NSCH, implying that the sample interviewed differed from the targeted child population in a systematic fashion [37]. Since response rates in the $\mathrm{NSCH}$ tend to be lower in urban areas and low-income and ethnic-minority populations, differential nonresponse bias might affect (most likely underestimate) the impact of neighborhood disadvantage, individual SES, and race/ethnicity on sleep problems [37]. However, the nonresponse adjustment to the sampling weights in the $\mathrm{NSCH}$ might have reduced the potential magnitude of these biases [37]. Lastly, the increased use of cell/mobile phone use in recent years, especially among young, minority, renters, and low-income adults, may be an additional source of noncoverage bias for landline only surveys such as the 2007 NSCH $[56,57]$.

In conclusion, the evidence presented here suggests that favorable neighborhood conditions and positive health behaviors are significantly associated with reduced risk of sleep problems in children, which, in turn, may support reductions in overall child health inequalities given the wideranging health effects of poor sleep. While behavioral changes such as increased physical activity, reduced television viewing and computer use, and reduced exposure to secondhand smoke can be beneficial in promoting children's sleep health, social policy measures aimed at improving the broader social and physical environments can be vital to improving overall child health in general and their sleep health in particular. Continued surveillance and monitoring of the prevalence of childhood sleep problems as well as its determinants are essential in order to better understand the role of broader societal factors and health behaviors and to design effective public health interventions, including public awareness and educational campaigns [46].

\section{Human Subjects Review}

No IRB approval was required for this study, which is based on the secondary analysis of a public-use federal database.

\section{Conflict of Interests}

The authors declare no conflict of interests.

\section{Disclaimer}

The views expressed are the authors' and not necessarily those of the Health Resources and Services Administration or the US Department of Health and Human Services.

\section{References}

[1] A. Smaldone, J. C. Honig, and M. W. Byrne, "Sleepless in America: inadequate sleep and relationships to health and wellbeing of our nation's children," Pediatrics, vol. 119, supplement 1, pp. S29-S37, 2007.

[2] M. Moore, H. L. Kirchner, D. Drotar, N. Johnson, C. Rosen, and S. Redline, "Correlates of adolescent sleep time and variability in sleep time: the role of individual and health related characteristics," Sleep Medicine, vol. 12, no. 3, pp. 239-245, 2011.

[3] H. R. Colten and B. M. Altevogt, Sleep Disorders and Sleep Deprivation: An Unmet Public Health Problem, Institute of Medicine, National Academies Press, Washington, DC, USA, 2006. 
[4] A. M. Moran and D. E. Everhart, "Adolescent sleep: review of characteristics, consequences, and intervention," Journal of Sleep Disorders: Treatment \& Care, vol. 1, no. 2, pp. 1-8, 2012.

[5] E. J. Paavonen, K. Räikkönen, J. Lahti et al., "Short sleep duration and behavioral symptoms of attention-deficit/hyperactivity disorder in healthy 7- to 8-year-old children," Pediatrics, vol.123, no. 5, pp. e857-e864, 2009.

[6] A. R. Wolfson and M. A. Carskadon, "Understanding adolescents' sleep patterns and school performance: a critical appraisal," Sleep Medicine Reviews, vol. 7, no. 6, pp. 491-506, 2003.

[7] H. Taras and W. Potts-Datema, "Sleep and student performance at school," Journal of School Health, vol. 75, no. 7, pp. 248-254, 2005.

[8] S. Ravid, I. Afek, S. Suraiya, E. Shahar, and G. Pillar, "Sleep disturbances are associated with reduced school achievements in first-grade pupils," Developmental Neuropsychology, vol. 34, no. 5, pp. 574-587, 2009.

[9] J. A. Owens, "Sleep disorders and attention-deficit/hyperactivity disorder," Current Psychiatry Reports, vol.10, no. 5, pp. 439-444, 2008.

[10] B. H. Hansen, B. Skirbekk, B. Oerbeck, T. Wentzel-Larsen, and H. Kristensen, "Associations between sleep problems and attentional and behavioral functioning in children with anxiety disorders and ADHD," Behavioral Sleep Medicine, 2013.

[11] R. Gruber, S. Michaelson, L. Bergmame et al., "Short sleep duration is associated with teacher-reported inattention and cognitive problems in healthy school-aged children," Nature and Science of Sleep, vol. 4, pp. 33-40, 2012.

[12] J. A. Mitchell, D. Rodriguez, K. H. Schmitz, and J. AudrainMcGovern, "Sleep duration and adolescent obesity," Pediatrics, vol. 131, no. 5, pp. 1-7, 2013.

[13] J. Liu, J. Hay, D. Joshi, B. E. Faught, T. Wade, and J. Cairney, "Sleep difficulties and obesity among preadolescents," Canadian Journal of Public Health, vol. 102, no. 2, pp. 139-143, 2011.

[14] G. E. Silva, J. L. Goodwin, S. Parthasarathy et al., "Longitudinal association between short sleep, body weight, and emotional and learning problems in Hispanic and Caucasian children," Sleep, vol. 34, no. 9, pp. 1197-1205, 2011.

[15] L. S. Nielsen, K. V. Danielsen, and T. I. A. Sørensen, "Short sleep duration as a possible cause of obesity: critical analysis of the epidemiological evidence," Obesity Reviews, vol. 12, no. 2, pp. 78-92, 2011.

[16] G. K. Singh and R. M. Ghandour, "Impact of neighborhood social conditions and household socioeconomic status on behavioral problems among US children," Maternal and Child Health Journal, vol. 16, supplement 1, pp. S158-S169, 2012.

[17] G. K. Singh and S. M. Yu, "The impact of ethnic-immigrant status and obesity-related risk factors on behavioral problems among US children and adolescents," Scientifica, vol. 2012, Article ID 648152, 14 pages, 2012.

[18] National Center for Health Statistics, The National Survey of Children's Health (NSCH), 2007: The Public Use Data File and Documentation, US Department of Health and Human Services, Hyattsville, Md, USA, 2009.

[19] A. R. Arman, P. Ay, N. P. Fis et al., "Association of sleep duration with socio-economic status and behavioural problems among schoolchildren," Acta Paediatrica, vol. 100, no. 3, pp. 420-424, 2011.

[20] K. Yolton, Y. Xu, J. Khoury et al., "Associations between secondhand smoke exposure and sleep patterns in children," Pediatrics, vol. 125, no. 2, pp. e261-e268, 2010.
[21] J. C. Spilsbury, A. Storfer-Isser, D. Drotar et al., "Sleep behavior in an urban US sample of school-aged children," Archives of Pediatrics and Adolescent Medicine, vol. 158, no. 10, pp. 988-994, 2004.

[22] J. G. Johnson, P. Cohen, S. Kasen, M. B. First, and J. S. Brook, "Association between television viewing and sleep problems during adolescence and early adulthood," Archives of Pediatrics and Adolescent Medicine, vol. 158, no. 6, pp. 562-568, 2004.

[23] H. M. Al-Hazzaa, A. O. Musaiger, N. A. Abahussain, H. I. Al-Sobayel, and D. M. Qahwaji, "Lifestyle correlates of selfreported sleep duration among Saudi adolescents: a multicentre school-based cross-sectional study," Child: Care, Health and Development, 2013.

[24] A. R. Pebley and N. Sastry, "Neighborhoods, poverty, and children's well-being," in Social Inequality, K. M. Neckerman, Ed., pp. 119-144, Russell Sage Foundation, New York, NY, USA, 2004.

[25] A. V. Diez Roux and C. Mair, "Neighborhoods and health," Annals of the New York Academy of Sciences, vol. 1186, pp. 125145,2010

[26] G. K. Singh, M. Siahpush, and M. D. Kogan, "Neighborhood socioeconomic conditions, built environments, and childhood obesity," Health Affairs, vol. 29, no. 3, pp. 503-512, 2010.

[27] M. A. Papas, A. J. Alberg, R. Ewing, K. J. Helzlsouer, T. L. Gary, and A. C. Klassen, "The built environment and obesity," Epidemiologic Reviews, vol. 29, no. 1, pp. 129-143, 2007.

[28] G. K. Singh, M. D. Kogan, P. C. Van Dyck, and M. Siahpush, "Racial/ethnic, socioeconomic, and behavioral determinants of childhood and adolescent obesity in the United States: analyzing independent and joint associations," Annals of Epidemiology, vol. 18, no. 9, pp. 682-695, 2008.

[29] Y. Xue, T. Leventhal, J. Brooks-Gunn, and F. J. Earls, "Neighborhood residence and mental health problems of 5- to 11-yearolds," Archives of General Psychiatry, vol. 62, no. 5, pp. 554-563, 2005.

[30] T. Leventhal and J. Brooks-Gunn, "The neighborhoods they live in: the effects of neighborhood residence on child and adolescent outcomes," Psychological Bulletin, vol. 126, no. 2, pp. 309-337, 2000.

[31] G. W. Evans, "The built environment and mental health," Journal of Urban Health, vol. 80, no. 4, pp. 536-555, 2003.

[32] J. C. Spilsbury, A. Storfer-Isser, H. L. Kirchner et al., "Neighborhood disadvantage as a risk factor for pediatric obstructive sleep apnea," Journal of Pediatrics, vol. 149, no. 3, pp. 342-347, 2006.

[33] I. Kawachi and L. F. Berkman, "Introduction," in Neighborhoods and Health, I. Kawachi and L. F. Berkman, Eds., pp. 1-19, Oxford University Press, New York, NY, USA, 2003.

[34] J. Heymann and A. Fischer, "Neighborhoods, health research, and its relevance to public policy," in Neighborhoods and Health, I. Kawachi and L. F. Berkman, Eds., pp. 335-347, Oxford University Press, New York, NY, USA, 2003.

[35] US Department of Health and Human Services, Healthy People 2020, 2013, http://www.healthypeople.gov/2020/default.aspx .

[36] Health Resources and Services Administration, Maternal and Child Health Bureau, The National Survey of Children's Health 2007: The Health and Well-Being of Children, A Portrait of States and the Nation, US Department of Health and Human Services, Rockville, Md, USA, 2009.

[37] S. J. Blumberg, E. B. Foster, A. M. Frasier et al., "Design and operation of the National Survey of Children's Health, 2007," Vital and Health Statistics, vol. 1, no. 55, pp. 1-149, 2012. 
[38] S. J. Blumberg, L. Olson, M. R. Frankel, L. Osborn, K. P. Srinath, and P. Giambo, "Design and operation of the National Survey of Children's Health, 2003," Vital and Health Statistics, vol. 1, no. 43, pp. 1-124, 2005.

[39] National Center for Health Statistics, The National Survey of Children's Health (NSCH), 2011-2012: The Public Use Data File and Documentation, US Department of Health and Human Services, Hyattsville, Md, USA, 2013, http://www.cdc.gov/ nchs/slaits/nsch.htm.

[40] National Center for Health Statistics, Health, United States, 2011 with Special Feature on Socioeconomic Status and Health, US Department of Health and Human Services, Hyattsville, Md, USA, 2012.

[41] National Center for Health Statistics, The National Survey of Children's Health (NSCH), 2003: The Public Use Data File, US Department of Health and Human Services, Hyattsville, Md, USA, 2005, http://www.cdc.gov/nchs/slaits/nsch.htm.

[42] G. K. Singh, S. M. Yu, and M. D. Kogan, "Health, chronic conditions, and behavioral risk disparities amongUS immigrant children and adolescents," Public Health Reports. In press.

[43] R. Wilkinson and M. Marmot, Social Determinants of Health: The Solid Facts, World Health Organization, Regional Office for Europe, Copenhagen, Denmark, 2nd edition, 2003.

[44] N. Adler, J. Stewart, S. Cohen et al., Reaching for a Healthier Life: Facts on Socioeconomic Status and Health in the US, The John D. and Catherine T. Macarthur Foundation Research Network on Socioeconomic Status and Health, San Francisco, Calif, USA, 2009.

[45] SUDAAN, Software for the Statistical Analysis of Correlated Data, Release 10.0.1, Research Triangle Institute, Research Triangle Park, NC, USA, 2009.

[46] Centers for Disease Control and Prevention, "Unhealthy sleeprelated behaviors-12 states, 2009," Morbidity and Mortality Weekly Report, vol. 60, no. 8, pp. 233-238, 2011.

[47] M. A. Stein, J. Mendelsohn, W. H. Obermeyer, J. Amromin, and R. Benca, "Sleep and behavior problems in school-aged children," Pediatrics, vol. 107, no. 4, article E60, 2001.

[48] National Sleep Foundation, "Children and sleep: sleep in America poll,” 2004, http://www.sleepfoundation.org/sites/default/ files/FINAL\%20SOF\%202004.pdf.

[49] National Sleep Foundation, “Teens and sleep: sleep in America poll," 2006, http://www.sleepfoundation.org/sites/default/ files/2006_summary_of_findings.pdf.

[50] A. R. Wolfson, M. A. Carskadon, C. Acebo et al., "Evidence for the validity of a sleep habits survey for adolescents," Sleep, vol. 26, no. 2, pp. 213-216, 2003.

[51] L. J. Meltzer, K. T. Avis, S. Biggs et al., “The children's report of sleep patterns (CRSP): a self-report measure of sleep for schoolaged children," Journal of Clinical Sleep Medicine, vol. 9, no. 3, pp. 235-245, 2013.

[52] C. A. Kushida, A. Chang, C. Gadkary, C. Guilleminault, O. Carrillo, and W. C. Dement, "Comparison of actigraphic, polysomnographic, and subjective assessment of sleep parameters in sleep-disordered patients," Sleep Medicine, vol. 2, no. 5, pp. 389-396, 2001.

[53] H. Werner, L. Molinari, C. Guyer, and O. G. Jenni, "Agreement rates between actigraphy, diary, and questionnaire for children's sleep patterns," Archives of Pediatrics and Adolescent Medicine, vol. 162, no. 4, pp. 350-358, 2008.

[54] S. W. Lockley, D. J. Skene, and J. Arendt, "Comparison between subjective and actigraphic measurement of sleep and sleep rhythms," Journal of Sleep Research, vol. 8, no. 3, pp. 175-183, 1999.

[55] S. Macintyre and A. Ellaway, "Neighborhoods and health: an overview," in Neighborhoods and Health, I. Kawachi and L. F. Berkman, Eds., pp. 20-42, Oxford University Press, New York, NY, USA, 2003.

[56] S. J. Blumberg and J. V. Luke, "Reevaluating the need for concern regarding noncoverage bias in landline surveys," American Journal of Public Health, vol. 99, no. 10, pp. 1806-1810, 2009.

[57] S. J. Blumberg and J. V. Luke, Wireless Substitution: Early Release of Estimates from the National Health Interview Survey, January-June 2008, National Center for Health Statistics, 2008, http://www.cdc.gov/nchs/data/nhis/earlyrelease/wireless200812.pdf. 


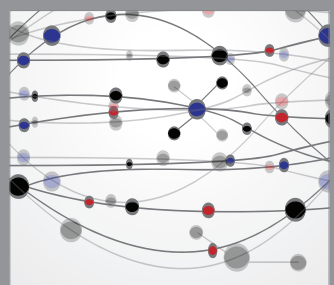

The Scientific World Journal
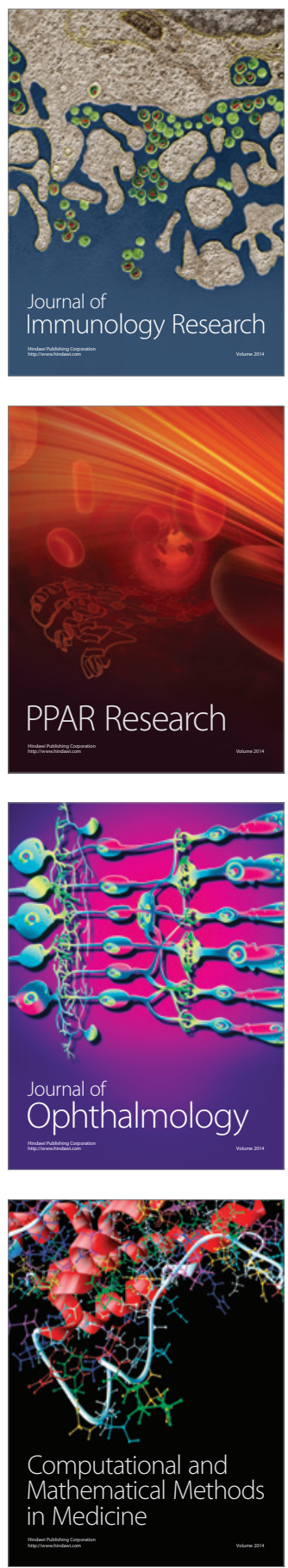

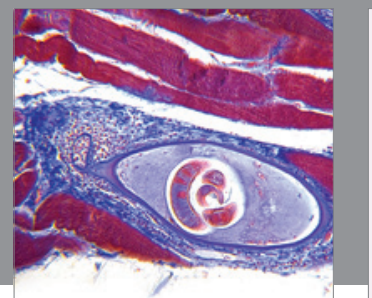

Gastroenterology

Research and Practice
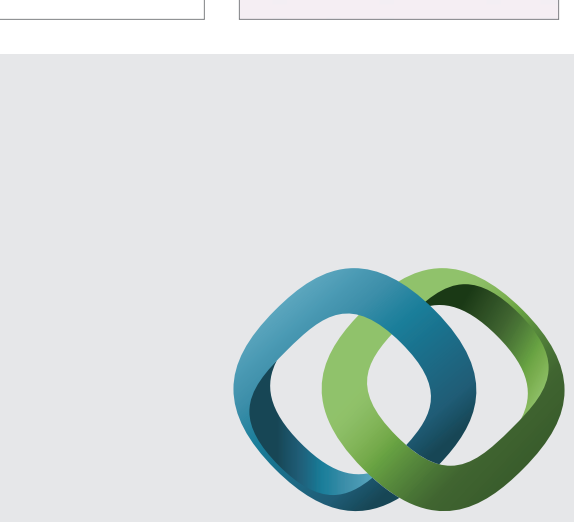

\section{Hindawi}

Submit your manuscripts at

http://www.hindawi.com
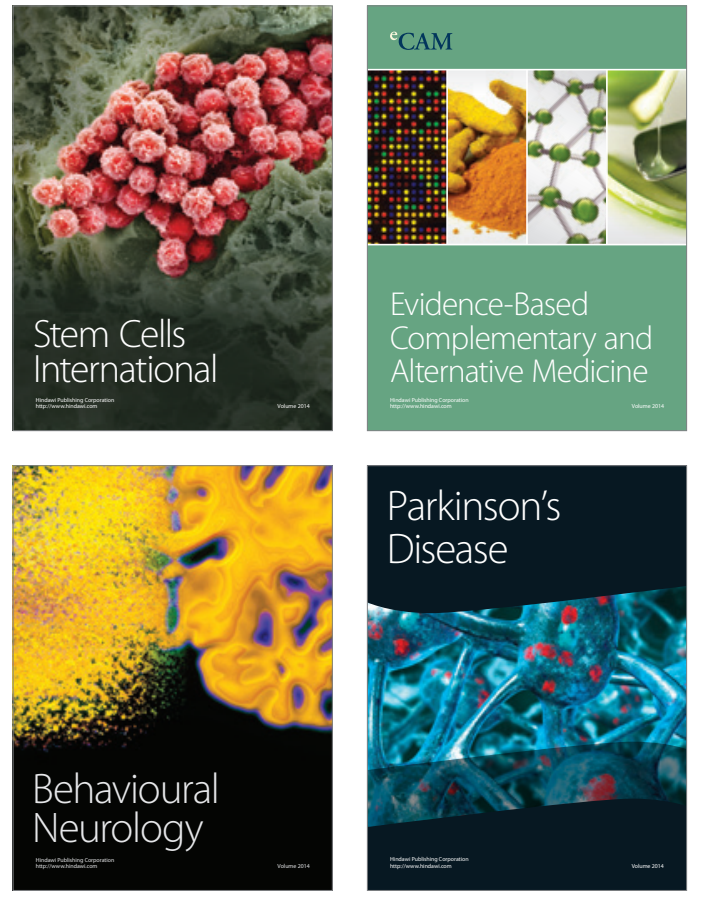
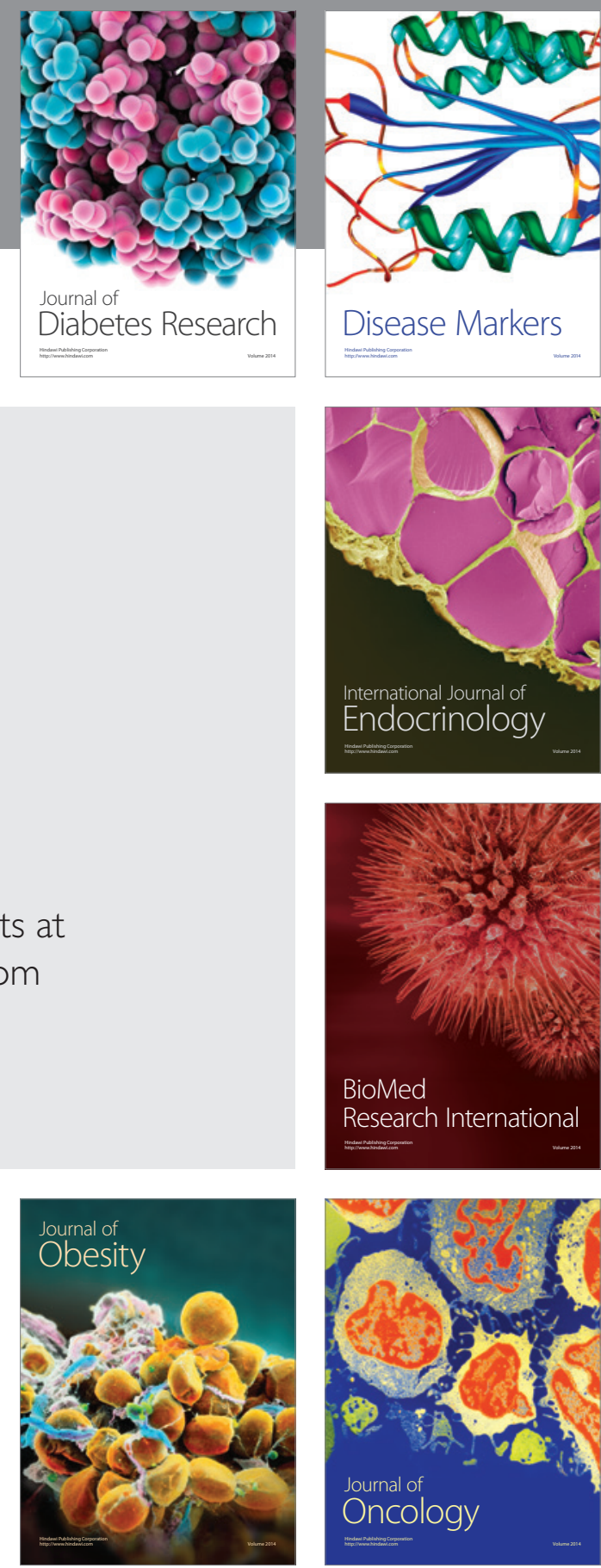

Disease Markers
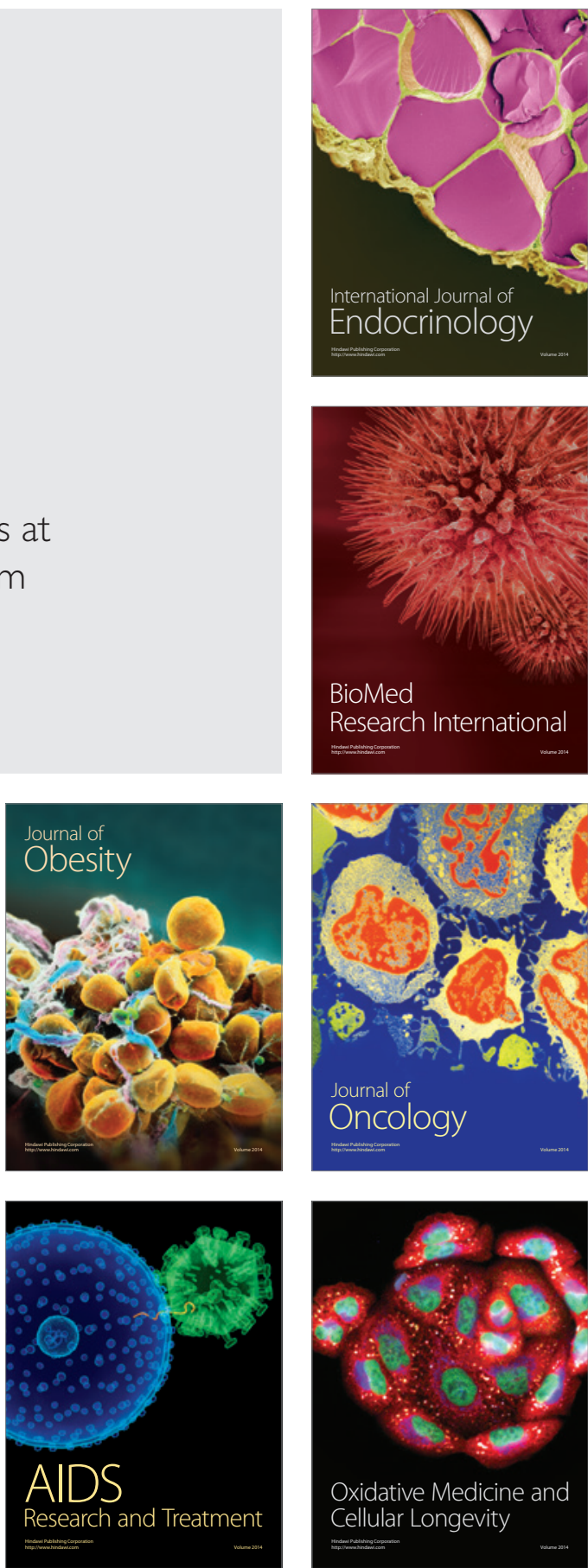